\title{
Determinants of Risk Behaviour in Livestock Development Programs: Evidence from South Africa's Kaonafatso Yadikgomo (Kyd) Scheme
}

\author{
Saul Ngarava*, Abbyssinia Mushunje, Amon Taruvinga, Peter Mukarumbwa, Simbarashe Tatsvarei, Ebenezer \\ T Megbowon \\ Department of Agricultural Economics and Extension, University of Fort Hare, South Africa \\ 201501225@ufh.ac.za,AMushunje@ufh.ac.za,ATaruvinga@ufh.ac.za, peerta@gmail.com, \\ tatsvarei.simbarashe@gmail.com,201415579@ufh.ac.za
}

\begin{abstract}
Risk plays a significant role in input use decisions and production of output in agricultural production. Understanding farmer risk attitudes and their responses to risk is significant in designing effective intervention programmes. Few studies have tried to identify how the introduction of a livestock programme has tended to influence farmer risk profile. The objective of the study was to highlight the determinants of risk behaviour in participants of a livestock development programme. The study was carried out in KwaZulu-Natal (KZN) Province of South Africa, utilising a purposive sample of 164 respondents who are part of the Kaonafatso Yadikgomo (KYD) Scheme. The cross-sectional survey collected data pertaining to the risk attitudes of the livestock farmers from an attitudinal scale as well as socio-economic and farm biophysical characteristics. Descriptive statistics and multiple linear regression were used to analyse the data. The results show that the livestock farmers were risk loving, with the risk attitude being influenced by the age of household head, monthly household income and experience in rearing cattle at the $p<0.1$ level. Furthermore, the source of income, herd size, reason for slaughtering cattle distance to the nearest water source and access to a dip tank had significant influence of attitude towards risk at the $p<0.05$ level. The study concludes that being part of a livestock development programme tends inflto uence the risk attitudes of the participants as the determinants were against a priori expectations.
\end{abstract}

\section{Keywords: Attitudinal scale, beef, farm biophysical, Likert scale, risk attitude, socio-economic}

\section{Introduction}

Risk plays a significant role in input use decisions and production of output in agricultural production (Orea \& Wall, 2002; Wanda, 2009). In attributing this, a significant portion of the research has focused on providing evidence regarding how risk impacts nature of decision making through ascertaining producer attitude toward risk (Hurley, 2010; Tae-hun, 2008). Understanding farmer risk attitudes and their responses to risk is significant in designing effective intervention programmes. Risk alternative questionnaires have been utilised in this regard, whilst others have utilised expected utility maximization based behaviour as well as observation of economic actions (Hurley, 2010; Lagerkvist, 2005; Lien, 2002; Serra, Goodwin, \& Featherstone, 2011; Wanda, 2009). Lagerkvist (2005) attests that much of the empirical work done has not sufficed as it has shown disparity with theory which is not reflected through individual behaviour. The literature has identified two contrasting poles in risk behaviour and attitude: risk aversion and risk loving. Risk-averse farmers utilise more (less) of a risk-reducing (increasing) factor than neutral farmers (Khan, Guttormsen, \& Roll, 2017; Makki, Somwaru, \& Vandeveer, 2002; Wanda, 2009). They tend to utilise an uneconomically optimal bundle of inputs (Khan et al., 2017). Furthermore, even when the output itself is variable, risk-averse farmers will not only take account of the expected output but its variability as well (Orea \& Wall, 2002).

According to Kassie, Yesuf, and Köhlin (2008) in risk aversion, an increase in variance makes the decision maker worse off, with most decision makers exhibiting decreasing absolute risk aversion. Thus the greater the variability, the less the resources devoted (Mccarthy, 2000). Furthermore, neglecting this risk-averse behaviour in agricultural modelling leads to overstating the output levels of risky endeavours. In addition, aversion to risk also influences total output and input use, with a more risk-averse producer, who dislikes income variability, preferring slightly lower output and expected returns if the variability of returns also declines (Makki et al., 2002; Mbuku, Kosgey, \& Kahi, 2006). Thus livestock farmers who are risk-averse are more willing to accept lower expected returns in avoiding the opportunity of unfavourable outcomes, thus having an impact on technology adoption (Kassie et al., 2008; Mbuku et al., 2006). In a related study by Flaten et al. (2005) comparing organic and conventional dairy farming in Norway, farmer perceptions were identified as significant in identifying their risk behaviour. There exists a literature gap in attributing 
livestock development programme to farmer risk attitude. True so for the Kaona fatso YA Dikgomo (KYD) scheme in South Africa.

The scheme was formally established as a government Act in 2007, with the aim to empower beef farmers through continuous improvement and innovation (Government of South Africa, 2007). The scheme is involved in training smallholder farmers in recording, comparing production systems and genetic improvement for the purpose of increasing production and profit, with 8400 farmers being part of the programme (ARC, 2012, 2015, 2016a). Benefits to being part of the scheme include access to animal health and production services, access to scientific methods in selecting animals to grow the livestock enterprise and accessing market advice. However, to date, there has been little to no inference on the impact on the risk of being part of the scheme. There appears a shortage of literature pertaining to how being part of the scheme has influenced the risk behaviour of the livestock farmers, offering a gap which can be pursued. Livestock farmer risk attitude studies suffer the same ill-fate as that of risk studies, of being scarce and one dimensional. Most studies simply allude to the risk profiles of livestock producers: whether they are riskaverse, neutral and/or loving (Hurley, 2010; Khan et al., 2017; Orea \& Wall, 2002; Wanda, 2009). The most notable absentee however has been studies that try to identify how the introduction of a livestock programme has tended to influence farmer risk profile.

Program impact can be evaluated by identifying how risk profile tends to compound the production risk. This also tends to speak to the continuity of the programme. For instance, a programme that tends to shift the risk behaviour of its participants and is unlikely to maintain such a risk profile after the programme has ended will only be as good as it subsists. The most glaring question to follow would then be: what will be the resulting impact if the livestock programme tends to shift both the production risk and the risk behaviour and the programme came to a halt? An ideal livestock programme would be one that tends to reduce variability (risk) whilst at the same time maintaining the risk profile of the farmers involved. Such aspects have not been evaluated in livestock development programmes in general and the KYD programme in particular. This offers a literature gap and an opportunity to further put the KYD programme under scrutiny for better-informed decisions. The objective of the study was to highlight the KYD programme participant risk behaviour and the determinants towards this behaviour.

\section{Material and Methods}

The study was carried out in KwaZulu-Natal (KZN) Province in South Africa, targeting Kaonafatso YA Dikgomo (KYD) scheme participants. The province was selected because it has the largest number of the KYD scheme active members, at 53\% of the country's total (ARC, 2016b). A cross-sectional survey was carried out to obtain a purposive sample of 164 respondents. The purposive sample was obtained through farmer field days, during which a questionnaire was the data collecting tool utilised. Purposive sampling was appropriate because it has less financial and temporal constraints, as well as that the farmers were conveniently grouped for the farmer field days. The sample size represented the number of farmers that were willing to partake in the study. Three farmer field days were targeted in November, 2017 in the following locations and the number of respondents: Godlwayo (42), Aitona (88) and Uitval (34). Godlwayo had 7 villages represented and Aitona with 6 villages whilst Uitval had 7 villages. Data collected pertained to the socio-economic variables as well as the risk attitudes of the livestock farmers. Farmers' risk attitudes were measured through a risk attitudinal scale in a questionnaire as used by Lagerkvist (2005). A 5 response option Likert scale was utilised as the measurement format. The Likert scale was utilised by authors such as Flaten et al. (2005) and Meuwissen, Huirne and Hardaker (2001) in ascertaining risk attitude, hence was appropriate for the study. The following ranking was used for the Likert scale (Lagerkvist, 2005): 1. Strongly disagree, 2. Disagree, 3. Not sure, 4. Agree, and 5. Strongly agree. The lower the individual statement score, the more the farmer takes measures in dealing with the risk in question. An example of a risk attitudinal statement and choice of option is observed below: 
Table 1: Likert-Scale Attitudinal Question

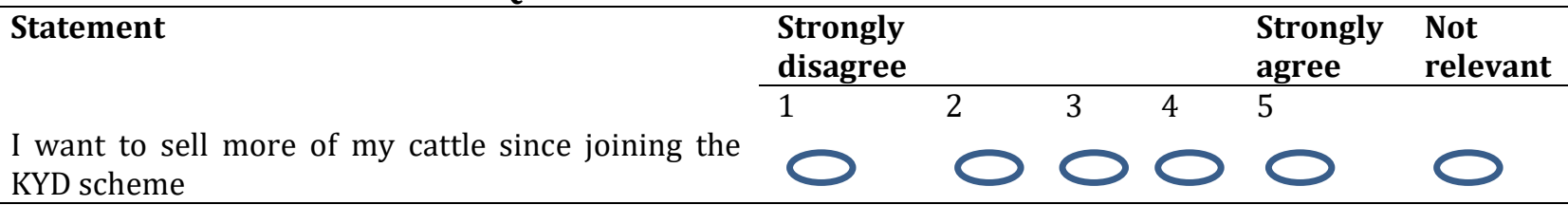

An individual lower total score hypothetically corresponds to higher risk aversion. The score for each Likert question was assigned a weight increasing from -2 for those who totally disagreed and +2 to those who strongly agree. Averaging a score of 0 corresponds to risk neutrality. Thus a positive score corresponds to risk affinity whilst a negative score represents risk aversion. The larger the magnitude, the larger the extremes of this risk behaviour. A total score was then attained through the summation of each Likert question. This individualistic total score was then used in a multiple linear regression as used by Hayran and Aykut, (2015) and Bishu et al. (2016) to ascertain factors having a bearing on the risk behaviour of KYD scheme participants in KZN Province, South Africa. A multiple linear regression model is a multivariate method appropriate when there are various explanatory variables and one dependent variable. It can be modelled as (Groebner, Shannon, Fry, \& Smiths, 2011; Hair Jnr, Black, Babin, \& Anderson, 2010):

$y=\alpha_{0}+\alpha_{1} x_{1}+\alpha_{2} x_{2}+\alpha_{3} x_{3}+\cdots+\alpha_{n} x_{n}+\varepsilon$

Where $y$ represents the Likert total score and $x_{1 \ldots n}$ represent the independent variables, with $\alpha_{1 \ldots n}$ being the coefficients. The following variables and their expected signs were utilised in the multiple linear regression.

Table 2: Variables Used in the Multiple Linear Regression Model

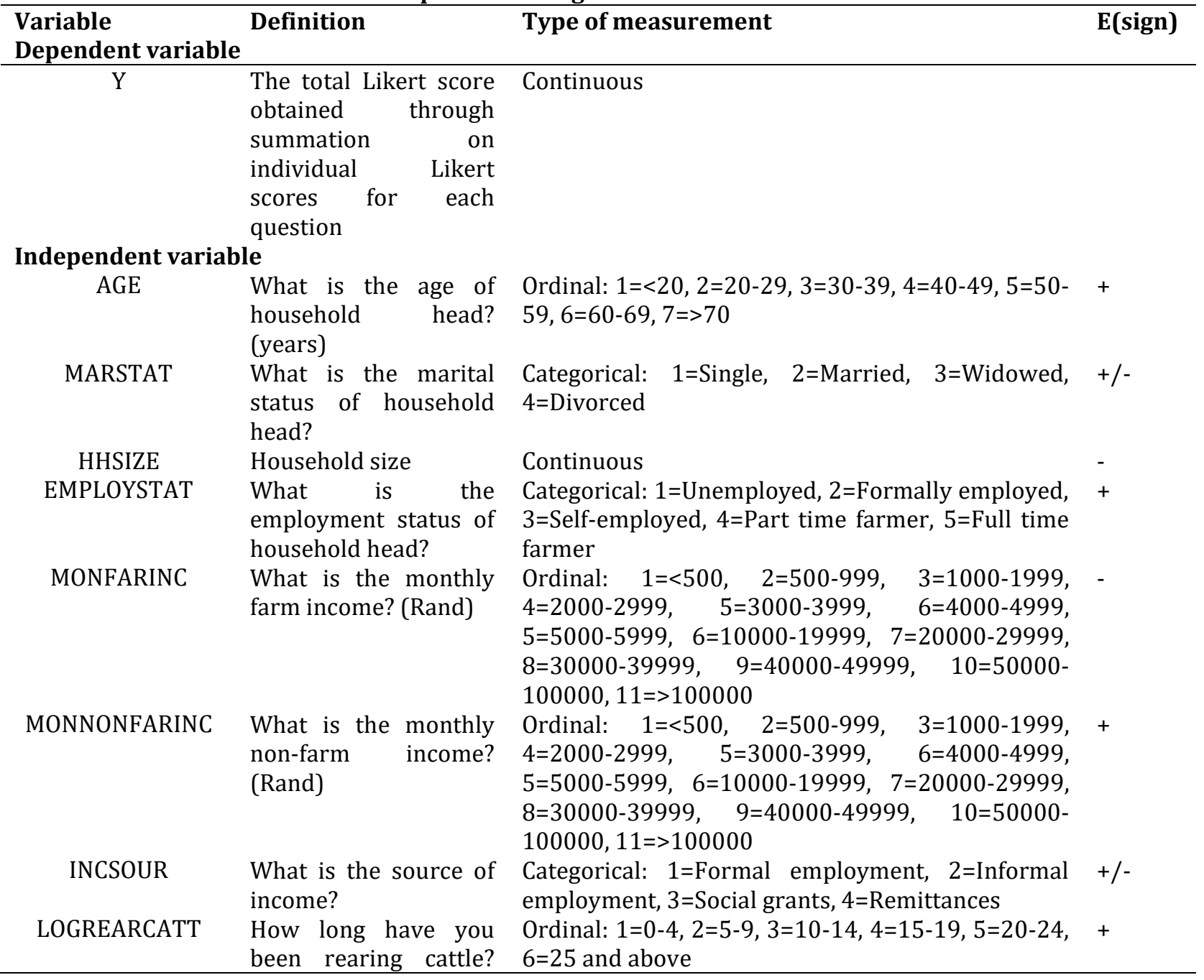




\begin{tabular}{|c|c|c|}
\hline & (years) & \\
\hline NOCATT & $\begin{array}{l}\text { How many cattle do } \\
\text { you have? }\end{array}$ & Continuous \\
\hline REASSLAU & $\begin{array}{l}\text { What is the reason for } \\
\text { slaughtering cattle? }\end{array}$ & $\begin{array}{l}\text { Categorical: } \quad 1=0 w n \\
\text { purposes, } \quad 3=\text { Culture } \\
\text { obligation, } 5=\text { Profit }\end{array}$ \\
\hline FARMACT & $\begin{array}{l}\text { What are the farm } \\
\text { activities undertaken? }\end{array}$ & $\begin{array}{l}\text { Categorical: } 1=\text { Livesto } \\
3=\text { Livestock + vegetal } \\
\text { vegetables }\end{array}$ \\
\hline DECMAK & $\begin{array}{l}\text { Who is the decision } \\
\text { maker? }\end{array}$ & $\begin{array}{l}\text { Categorical: } 1=\text { Hous } \\
\text { whole family, } 3=\text { Relat } \\
\text { family (group) }\end{array}$ \\
\hline DISTWATE & $\begin{array}{l}\text { What is the distance to } \\
\text { the nearest water } \\
\text { source? (metres) }\end{array}$ & Continuous \\
\hline TRAINI & $\begin{array}{l}\text { Do you have training } \\
\text { in rearing cattle? }\end{array}$ & Dummy: $1=$ Yes, $2=$ No \\
\hline ACCTOVET & $\begin{array}{l}\text { Do you have access to } \\
\text { veterinary services? }\end{array}$ & Dummy: $1=$ Yes, $2=$ No \\
\hline ACCTODIP & $\begin{array}{l}\text { Do you have access to } \\
\text { a dip tank? }\end{array}$ & Dummy: $1=$ Yes, $2=$ No \\
\hline
\end{tabular}

The multiple linear regression was thus modelled as follows:

$$
\begin{aligned}
Y=\alpha_{0}+\alpha_{1} A G E & +\alpha_{2} \text { MARSTAT }+\alpha_{3} \text { HHSIZE }+\alpha_{4} \text { EMPLOYSTAT }+\alpha_{5} \text { FARINC }+\alpha_{6} \text { NONFARINC } \\
& +\alpha_{7} \text { INCSOUR }+\alpha_{8} \text { LOGREARCATT }+\alpha_{9} \text { NONCATT } \\
& +\alpha_{10} \text { REASSLAU }+\alpha_{11} \text { FARMACT }+\alpha_{12} \text { DECMAK }+\alpha_{13} \text { DISTWATE }+\alpha_{14} \text { TRAINI } \\
& +\alpha_{15} \text { ACCTOVET }+\alpha_{16} \text { ACCTODIP }+v_{i}
\end{aligned}
$$

Where $\alpha_{1}-\alpha_{16}$ represent the coefficients associated with the explanatory variables that influence farmer risk attitude score $Y . v_{i}$ is the random error term with mean zero and variance 1

For reliability of the attitudinal scale, Cronbach's coefficient alpha was used in measuring the degree of communal variation:

$$
\propto=\frac{b}{b-1}\left(1-\frac{\sum \sigma_{i}^{2}}{\sigma_{y}^{2}}\right)
$$

Where $b$ is the number of statements in the scale, $\sigma_{i}^{2}$ is the variance of the $i$ the statement, and $\sigma_{y}^{2}$ is the total variance of the $b$-item scale.

\section{Results and Discussion}

Seventy percent of the respondents had a male-headed household, with 79.9\% having an age of more than 40 . Forty-two percent of the household heads were married, with $55.4 \%$ attaining education not enough to be gainfully employed exhibited by the $59.1 \%$ of the unemployed household heads. Fifty-two percent of the respondents' household head had a monthly farm income of less than R500 whilst $41.5 \%$ had a non/off-farm income of R500, with $63.2 \%$ relying on social grants as a source of income. The mean number of years to being part of the KYD programme was $8.03(\approx 8)$ years, with household size and dependency ratio averaging $6.58(\approx 7)$ and $1.26(\approx 1)$ respectively. The average cattle herd size was $18.96(\approx 19)$ cattle, with a mean distance to the market of $2.6 \mathrm{~km}$. Figure 1 shows that $64.4 \%$ of the respondents agree that they prefer to sell their livestock since joining the KYD scheme. Furthermore, $81.8 \%$ of the respondents are willing to continue with the experiences of the KYD scheme even if it ceases, whilst $68 \%$ agree to have improved in the use of conventional livestock technologies and systems. However, $69.8 \%$ of the respondents are either unsure or disagree in high cost of maintaining their livestock. A further $77.2 \%$ are indifferent and disagree to the scheme inducing income diversity, with $31.5 \%$ agreeing to discontinue the programme if the government support leaves. Fifty percent of the respondents indicate that they depend on the scheme for everything related to livestock rearing. 


\section{Figure 1: Farmer Behaviour since Joining the KYD Programme}

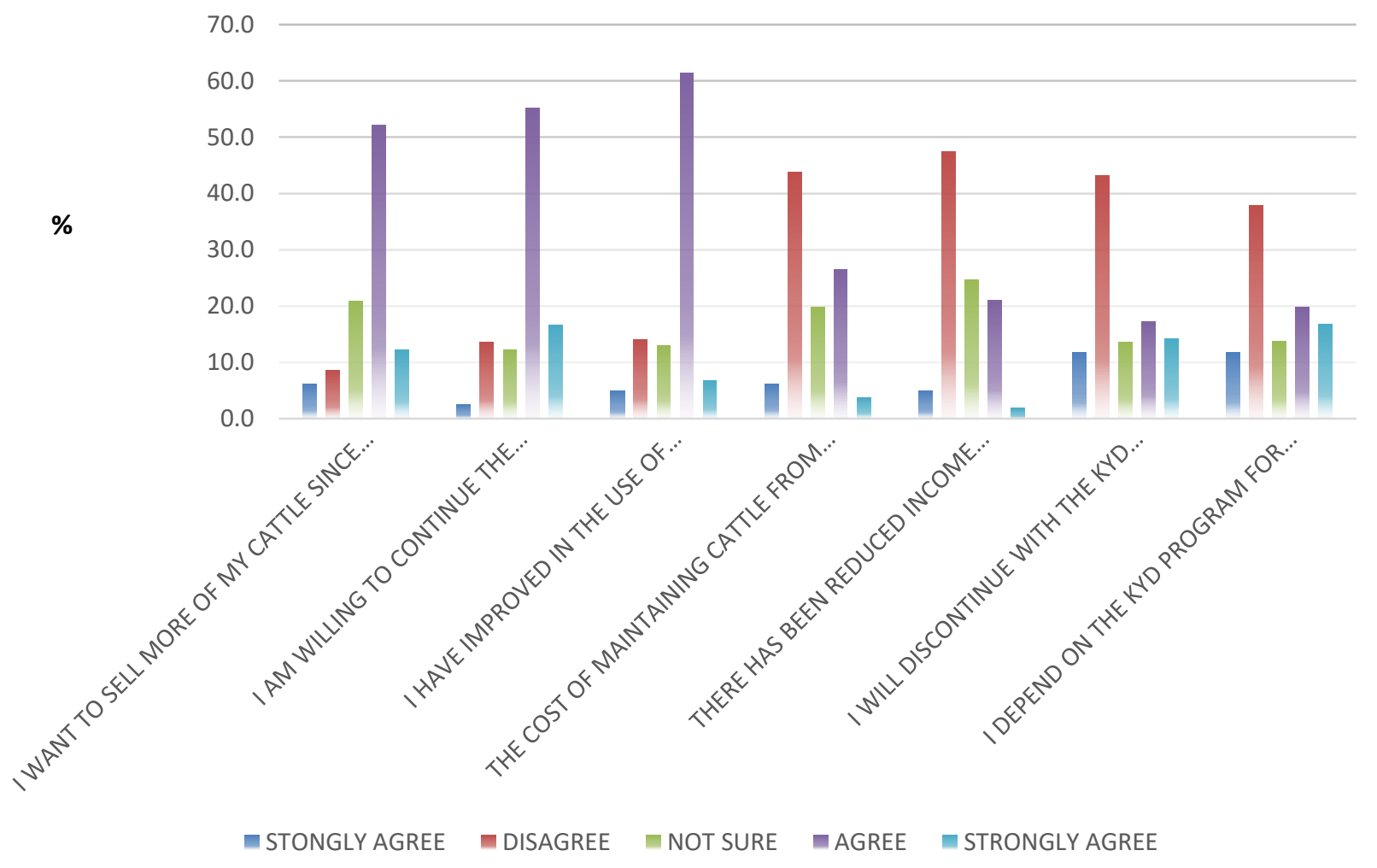

Table 3 shows that the Likert-scaled questions had a Cronbach's Alpha statistic of 0.538 , indicating that the questions were relatively reliable. The Hotteling's T-squared test is significant at the $p<0.01$ level, signifying a significant difference in the means of the Likert scores. The mean scores $(\approx 4)$ and the negative skewness show that the respondents strongly agreed with the programme improving their propensity to sell, continue with the programme experiences and well as improved use of convectional technologies. The (ARC, 2011, $2015)$ highlighted the increased off take, commercialisation and market participation exhibited by KYD programme participants. However, the mean score of $(\approx 3)$ highlight and the positive skewness indicate that the respondents disagreed with the programme exhibiting high maintenance costs, reduced income diversity, to discontinue when the financier leaves and well as depending on the programme.

Table 3: Farmer behaviour since joining the KYD programme

\begin{tabular}{|c|c|c|c|c|c|c|}
\hline & Min & Max & Mean & Std. Dev & Skewness & Kurtosis \\
\hline Prefers to sell more commercialise & 1 & 5 & 3.56 & 1.019 & -0.940 & 0.532 \\
\hline Willingness to continue with experiences & 1 & 5 & 3.70 & 0.982 & -0.868 & 0.239 \\
\hline Improved use of conventional methods & 1 & 5 & 3.51 & 0.984 & -1.050 & 0.352 \\
\hline High cost of maintaining & 1 & 5 & 2.78 & 1.028 & 0.319 & -0.927 \\
\hline Reduced income diversity & 1 & 5 & 2.67 & 0.925 & 0.460 & -0.655 \\
\hline Discontinuity when the government leaves & 1 & 5 & 2.79 & 1.268 & 0.477 & -0.984 \\
\hline Dependency on the programme & 1 & 5 & 2.92 & 1.313 & 0.285 & -1.200 \\
\hline \multicolumn{7}{|l|}{ Reliability test } \\
\hline Cronbach's Alpha & & 0.538 & & & Sig & \\
\hline \multirow[t]{2}{*}{ Hotelling's T-squared } & & 91.825 & & & 0.000 & \\
\hline & & & $\begin{array}{l}\text { Mean } \\
\text { Square }\end{array}$ & $\mathrm{F}$ & & \\
\hline \multirow[t]{2}{*}{ ANOVA with Tukey's Test for Nonadditivity } & \multicolumn{2}{|c|}{ Between items } & 30.416 & 153.452 & 0.000 & \\
\hline & \multicolumn{2}{|c|}{$\begin{array}{l}\text { Nonadditivity } \\
\text { residual }\end{array}$} & 28.444 & 29.123 & 0.000 & \\
\hline
\end{tabular}


Figure 2: Distribution of Respondents' Individual Total Likert Scores

15

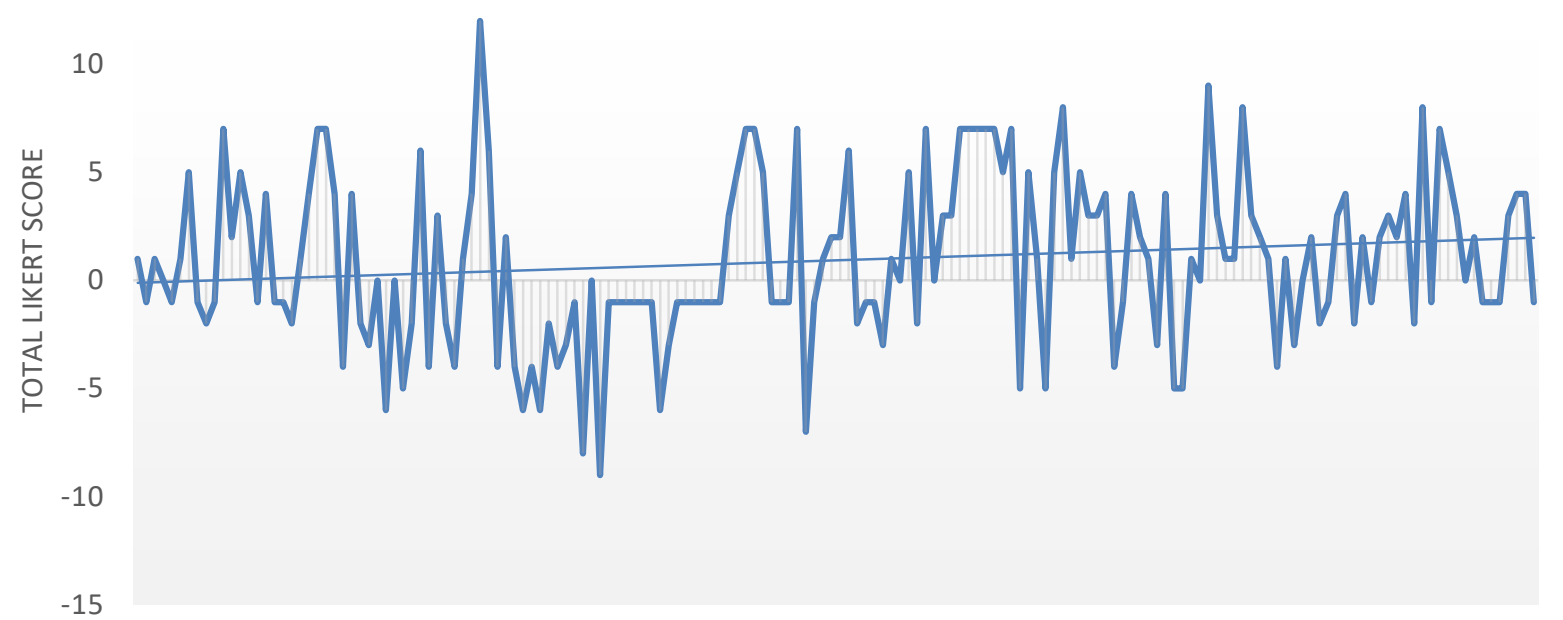

Figure 2 shows the distribution of the total Likert scores for the 164 respondents. The general positive trend indicates the affinity of the respondents to risk-taking. Table 4 shows the determinants of risk behaviour of KYD scheme participants. The variables significantly represent determinants of risk behaviour of KYD scheme participants at the $\mathrm{p}<0.01$ level. The $\mathrm{R}^{2}$ value shows that these variables account for a low $20.4 \%$ of the variables having an influence on the risk behaviour. This is similar to other studies which obtained the low coefficient of determinant mainly attributed to the perceptions and attitudes which tend to differ from one respondent to another (Aditto, Gan, \& Nartea, 2012; Flaten et al., 2005; Meuwissen et al., 2001). The table shows that age of household head, monthly household farm income, and experience in rearing cattle have a significant bearing on the risk behaviour of KYD scheme participants at the $p<0.1$ level. The source of income, herd size, the reason for slaughtering cattle, distance to the nearest water source and access to a dip tank had a significant influence on the risk behaviour at the $p<0.05$ level.

Table 4: Multiple Linear Regression Results of Factors Influencing Risk Attitude

\begin{tabular}{|c|c|c|c|}
\hline Variable & B & Sig & Beta \\
\hline Age of household head & $0.528^{*}$ & 0.059 & 0.175 \\
\hline Marital status of household head & 0.327 & 0.390 & 0.075 \\
\hline Total household size & 0.120 & 0.141 & 0.128 \\
\hline Employment status of the household head & 0.430 & 0.130 & 0.146 \\
\hline Monthly household farm income & $-0.263^{*}$ & 0.087 & -0.178 \\
\hline Monthly household off/non-farm income & -0.224 & 0.174 & -0.144 \\
\hline Source of income & $-0.967 * *$ & 0.040 & -0.188 \\
\hline How long have you been rearing cattle & $-0.428 *$ & 0.057 & -0.175 \\
\hline Number of cattle & $-0.049 * *$ & 0.026 & -0.217 \\
\hline Reasons for slaughtering cattle & $-0.511^{* *}$ & 0.016 & -0.213 \\
\hline Farming activities undertaken & 0.251 & 0.392 & 0.071 \\
\hline Decision maker & 0.259 & 0.471 & 0.059 \\
\hline Distance to nearest water source & $-5.879 \mathrm{E}-05^{* *}$ & 0.036 & -0.163 \\
\hline Training in rearing cattle & -1.09 & 0.141 & -0.123 \\
\hline Access to veterinary services & -1.06 & 0.184 & -0.114 \\
\hline Access to dip tank & $3.67^{* *}$ & 0.013 & 0.208 \\
\hline Constant & $23.2^{* * *}$ & 0.000 & 2.88 \\
\hline \multicolumn{4}{|l|}{ Model Summary } \\
\hline 0.00 & & & \\
\hline $\mathrm{R}^{2}$ & & & \\
\hline Adjusted $\mathrm{R}^{2}$ & & & \\
\hline 2.23 & & & \\
\hline
\end{tabular}


The age of household head had a positive significant influence on the risk behaviour of KYD scheme participants. The age of the household head accounted for $17.5 \%$ influence on the risk behaviour of the respondents. This is due to the risk-taking endeavours as the farmers become older (Aye \& 0ji, 2007). Experience also has a bearing on such behaviours, with previous experiences ensuring better preparedness of future risks and uncertainties (Van Winsen et al., 2016). The older people are more resource endowed, ensuring risk mitigation strategies, thus are prepared to venture and have an affinity for risk-taking. However, experience in farming had a $17.5 \%$ account on the risk behaviour of the KYD scheme participants, negatively influencing such behaviour. The more experienced the farmer was in rearing cattle, the more risk averse the farmer was, contrary to Aye and 0ji, (2007). This is relative to the experiences of the farmers. Climate change induced recurrent droughts have had a negative bearing on the risk affinity behaviour of livestock farmers. This is not privy to less experienced farmers, who are willing to take risks. Cattle production requires long-term investment and orientation, in its nature not a quick return enterprise, and thus not appealing to risk takers. Only through experience, can such a decision be reached.

Monthly farm income had a negative significant influence on the risk behaviour of KYD scheme participants, accounting for $17.8 \%$ of this behaviour. Thus the more the farm income, the more risk averse the farmers become. This could be due to a livelihood-livestock enterprise nexus, where most of the respondents that had high farm income were overly reliant upon farming for their livelihood. Hence, they are less likely to experiment and expose to risk unless their livelihoods be compromised. This was contrary to Bishu et al. (2016) and Meuwissen, Huirne, and Hardaker, (2001) who found that the higher the farm income, the less risk averse the farmers. However, Mischra and Goodwin, (2006) indicated that it is actually the amount of off/non-farm income that would make farmers less risk-averse. This is supported by Aye and 0ji (2007), Flaten et al. (2005) and Meuwissen, Huirne, and Hardaker, (2001) who highlighted that it is actually the total income that had a much significant influence on the risk attitude of farmers.

Table 4 also shows that the source of income had a negative significant influence on the risk behaviour of the KYD scheme participants, with an account of $18.8 \%$ of this behaviour. Thus, as the source of income shifted from formal employment to informal employment, social grants and remittances, the more risk averse the farmers. This amounts to the amount of income that can be obtained from each source. Remittances and social grants have low incomes; hence the farmers are reluctant in taking risk lest their livelihoods be compromised. The herd size and the reason for slaughtering cattle had a negative significant influence on the risk behaviour of KYD scheme participants. They both accounted for $21.7 \%$ and $21.3 \%$ of this risk behaviour respectively. The herd size was surprisingly indicating that the larger the herd size, the more risk averse the farmer. Bardhan et al. (2006) found that as herd size increases, the more risk averse the farmers, mainly attributed to farmers paying more attention to their farming. This was contrary to Bishu et al. (2016) who found that in Ethiopia, as herd size increased, farmers became less risk-averse. This was also supported by Van Winsen et al. (2016) and Xiao et al. (2001) who indicated that the larger the farm size, the less risk averse the farmer.

The results further show that as a reason for slaughtering changes from own consumption to religious purposes, cultural tradition, financial obligation and profit, the less risk averse the farmers. The profit potential induces the farmer to be less risk-averse in the endeavour to maximize on returns. Distance to water source and access to dip tank accounted for $16.3 \%$ and $20.8 \%$ for the risk behaviour of KYD scheme participants respectively. However, distance to water source had a negative influence whilst the access to dip tank had a positive influence on this risk behaviour. These results indicate that the further the distance to water source, the more risk averse the farmers would be. This will be congruent with the enterprise itself, which requires large volumes of water from watering the animals to providing vaccines and dipping them as well. Access to a dip tank had the a priori positive expectation insinuating that a farmer has risk affinity if they have access to a dip tank. This assures the reduction of external parasitic diseases, thereby increasing the risk tolerance of the farmers.

\section{Conclusion}

Livestock development programmes have had an influence on the risk behaviour of livestock keepers. This has a major impact on the sustainability and continuity the livestock development programmes. The objective of the study was to highlight the KYD programme participant risk behaviour and the determinants towards 
this behaviour. In conclusion, being part of the livestock development programme made the participants less risk-averse. This is due to the assurance of the programme in providing the key technical and material support in their livestock enterprises, providing room for the experimentation. The farmers prefer to participate in markets more and are willing to continue with the teaching of the programme even when it comes to an end, with some overly relying on the programme for everything related to livestock rearing. Furthermore, factors such as the age of household head, monthly household farm income, experience in rearing cattle, the source of income, herd size, the reason for slaughtering cattle distance to the nearest water source and access to a dip tank had a significant influence on the risk behaviour. The results show that the risk behaviour is mainly determined by inherent farmer characteristics, with less institutional factors having a bearing on the risk behaviour. The programme has thus been beneficial in eliminating exogenous risk perceptions. This has a two-tier effect: 1) More risk affinity for the livestock farmers; and 2) The participants become overly reliant on the programme, and any alteration from this new norm would have a negative influence. The study recommends that institutions such as extension could have a role to play in influencing behaviour especially given that the farmers exhibit a propensity to commercialise and have risk affinity.

\section{References}

Aditto, S., Gan, C. \& Nartea, G. V. (2012). Sources of Risk and Risk Management Strategies: The Case of Smallholder Farmers in a Developing Economy. In N. Banaitiene (Ed.), Risk Management-Current Issues and Challenges, 449-475.

ARC. (2011). Annual Report 2010-2011. Pretoria, South Africa.

ARC. (2012). National Beef Recording and Improvement Scheme. Irene, South Africa. Retrieved from http://www.arc.agric.za/arc-api/Newsletter Library/National Beef Recording and Improvement Scheme Newsletter 2012.pdf

ARC. (2015). ARC Annual Report 2014/2015. ARC Annual Report. Pretoria, South Africa.

ARC. (2016a). Annual Beef Bulletin. Irene, South Africa. Retrieved from http://www.arc.agric.za/ARC Newsletters/ARC Annual Beef Bulletin - 2016.pdf

ARC. (2016b). Annual Report 2015/16. Pretoria, South Africa.

Aye, G. C. \& Oji, K. O. (2007). Effect of Poverty on Risk Attitudes of Farmers in Benue State, Nigeria. In 12th Annual Conference on Econometric Modelling for Africa. Cape Town, South Africa 4-6 July.

Bardhan, D., Daba, Y. P. S., Tewari, S. K. \& Kumar, A. (2006). An assessment of the risk attitude of dairy farmers in Uttaranchal (India). In International Association of Agricultural Economists Conference. Gold Coast, Australia, August 12-18.

Bishu, K. G., O’Reilly, S., Lahiff, E. \& Steiner, B. (2016). Cattle farmers' perceptions of risk and risk management strategies: evidence from Northern Ethiopia. Journal of Risk Research, 9877, 1-20.

Flaten, O., Lien, G., Koesling, M., Valle, P. S. \& Ebbesvik, M. (2005). Comparing risk perceptions and risk management in organic and conventional dairy farming: empirical results from Norway. Livestock Production Science, 95, 11-25.

Government of South Africa. (2007). Agricultural Improvement Act, 1997 § (2007). South Africa.

Groebner, D. F., Shannon, P. W., Fry, P. C. \& Smiths, K. D. (2011). Business Statistics: A Decision-Making Approach (8th Edition). New Jersey, USA: Prentice Hall.

Hair Jnr, J. F., Black, W. C., Babin, J. B. \& Anderson, R. E. (2010). Multivariate Data Analysis. Pearson Prentice Hall.

Hayran, S. \& Aykut, G. (2015). Risk Perception and Management Strategies in Dairy Farming: A Case of Adana Province of Turkey. Turkish Journal of Agriculture - Food Science and Technology, 3(12), 952-961.

Hurley, T. M. (2010). A Review of Agricultural Production Risk in the Developing World.

Kassie, M., Yesuf, M. \& Köhlin, G. (2008). The Role of Production Risk in Sustainable Land- Management Technology Adoption in the Ethiopian Highlands. Environment for Development. Addis Ababa, Ethiopia.

Khan, A., Guttormsen, A. \& Roll, K. H. (2017). Production risk of pang as (Pangasiushy pophthalmus) fish farming. Aquaculture Economics \& Management, 0(0), 1-17.

Lagerkvist, C. J. (2005). Assessing farmers' risk attitudes based on economic, social, personal, and environmental sources of risk: evidence from Sweden. In American Agricultural Economics Association. Providence, 24-27. 
Lien, G. (2002). Non-parametric estimation of decision makers' risk aversion. Agricultural Economics, 27, 7583.

Makki, S. S., Somwaru, A. \& Vandeveer, M. (2002). Decoupled Payments and Farmers' Production Decisions Under Risk. Decoupled Payments in a Changing Policy Setting. Economic Research Service, USDA.

Mbuku, S. M., Kosgey, I. S. \& Kahi, A. K. (2006). Identification systems and selection criteria of pastoral goat keepers in northern Kenya - Implications for a breeding program. Tropentag, 11-13.

Mccarthy, N. (2000). An Economic Analysis of the Effects of Production Risk on the Use and Management of Common-Pool Rangelands. In N. McCarthy, B. Swallow, M. Kirk, \& P. Hazell (Eds.), Property Rights, Risk, and Livestock Development in Africa, 155-190.

Meuwissen, M. P. M., Huirne, R. B. M. \& Hardaker, J. B. (2001). Risk and risk management: an empirical analysis of Dutch livestock farmers. Livestock Production Science, 69, 43-53.

Mischra, A. K. \& Goodwin, B. K. (2006). Revenue insurance purchase decisions of farmers. Journal of Applied Economics, 38, 149-159.

Orea, L. \& Wall, A. (2002). Decomposing Productivity Growth (12 No. 2002). Asturia, Spain.

Serra, T., Goodwin, B. K. \& Featherstone, A. M. (2011). Risk behaviour in the presence of government programs. Journal of Econometrics, Elsevier. https://doi.org/10.1016/j.jeconom.2009.10.005

Tae-hun, K. I. M. (2008). The Measurement of Farmers Risk Attitudes Using a Non-Structural Approach. Journal of Rural Development, 31(2), 63-80.

Van Winsen, F., De Mey, Y., Lauwers, L., Van Passel, S., Vancauteren, M. \& Wauters, E. (2016). Determinants of risk behaviour: Effects of perceived risks and risk attitude on farmers' adoption of risk management strategies. Journal of Risk Research, 19(1), 56-78.

Wanda, 0. (2009). Production Risk and Input Use in Banana Production in Uganda. Makerere University.

Xiao, J. J., Alhabeeb, M. J., Hong, G. S. \& Haynes, G. (2001). Attitude toward risk and risk-taking behavior of business-owning families. The Journal of Consumer Affairs, 35, 307-325. 